\title{
STATUS OF PLS 2-GEV ELECTRON LINAC
}

\author{
S.H. Nam, Y.J. Han, K.R.Kim, Y.C.Kim \\ Pohang Accelerator Laboratory, POSTECH \\ Pohang, 790-784 Republic of Korea
}

\begin{abstract}
The $2 \mathrm{GeV}$ electron linac at the Pohang accelerator laboratory (PAL) has been operated continuously as a full energy injector since its completion on December 1994. The linac system has been continuously upgraded to improve overall system stability and reliability, as well as to increase final injection energy to $2.5 \mathrm{GeV}$. Eight klystron tubes out of 11 tubes are survived since the beginning of linac operation. The average high voltage operation time of the survived klystrons (E-3712, Toshiba) has been reached near 35,000 hours as of December 1998. Current overall system availability is well over $90 \%$. In this paper, we report the major linac system performance as well as relevant machine statistics, the electron beam parameter measurement, and operational characteristics of cooling water system.
\end{abstract}

\section{INTRODUCTION}

PLS linac [1] has been injecting 2-GeV electron beams to Pohang Light Source (PLS) storage ring (SR) since September 1994. The linac klystron modulator system (K\&M system) has started its normal operation at the end of 1993, and the total accumulated high voltage run time of the oldest unit has reached beyond 40,000 hours. At the end of 1997 we have installed one more additional K\&M module (total 12 modules with 44 accelerating structures) for the higher beam energy margin. The K\&M system is normally operating in 70 to $80 \%$ of the rated peak power level to avoid the multipactoring phenomena occurring occasionally in random fashion in the waveguide networks and accelerating structures. The sum of all the high voltage run time of the K\&M system is approximately 420,000 hours as of December 1998.

In this paper we have reviewed overall system performance statistics of the high power K\&M system of the PLS linac for the period of September 1994 to December 1998. In addition, the construction of the MK12 module and the bunch length of electron beam measurement and the cooling water system are reviewed.

\section{K\&M SYSTEM OVERVIEW}

Key features of the K\&M system design include 3phase SCR phase controlled DCHV power supply, resonant charging of the PFN, resistive De-Q'ing, endof-line clipping with thyrite disks, pulse transformer with 1:17 step-up turns ratio, and high power thyratron switch. The major operational parameters of the K\&M system (PLS-200MW modulator) are listed in Table-1.

Table 1: K\&M operation parameter summary.

\begin{tabular}{|l|l|}
\hline Peak beam power & 200MWmax. (400kV @ 500A) \\
\hline Beam vol. pulse width & ESW 7.5 $\mu \mathrm{s}, 4.4 \mu \mathrm{s}$ flat-top \\
\hline Pulse rep. rate & $120 \mathrm{pps}$ max. (currently 30pps) \\
\hline PFN impedance & $2.64 \Omega$ (5\% positive mismatch) \\
\hline Voltage stabilization & $\begin{array}{l}\text { SCR, DC feedback \& } \\
5 \% \text { De-Q'ing }\end{array}$ \\
\hline Pulse transformer & $\begin{array}{l}1: 17 \text { (turn ratio), } \\
\mathrm{L}_{\mathrm{L}}: 1.3 \mu \mathrm{H}, \mathrm{C}_{\mathrm{D}}: 69 \mathrm{nF}\end{array}$ \\
\hline Thyratron switch & $\begin{array}{l}\text { heating factor: } 46.8 \times 10^{9} \mathrm{VApps}, \\
8.5 \mathrm{kA} \text { peak anode current }\end{array}$ \\
\hline Klystron tube & $\begin{array}{l}\text { drive power: 300W, } \\
\text { efficiency::40\%, gain: } \sim 53 \mathrm{~dB}, \\
\text { peak power:80/65 MW } \\
\text { (currently running at 50 to } \\
\text { 65MW) }\end{array}$ \\
\hline
\end{tabular}

For the fault free stable operation of the system the thyratron tube is one of the most important active components which require continuous maintenance and adjustment. Performance evaluations of the thyratrons are underway. This effort is initiated to improve the system from the frequent occurring fault caused by the irregular recovery action of the thyratrons, which strongly depends upon the reservoir control.

There are three types of system's interlocks, namely dynamic, static, and personal protection interlocks. All the static fault activation is initiated by the relay logic circuit, and dynamic faults which require fast action response are activated using the electronic comparator circuit. When the system operation is interrupted by the static fault it can be recovered either by the automatic remote control computer or by the manual reset switch.

\section{SYSTEM AVAILABILITY STATISTICS}

Since the completion of the PLS 2-GeV linac in December 1993 all the K\&M systems have been operating continuously except scheduled short term and long term maintenance shut down. Fig. 1 shows the accumulated run times of klystron and thyratron tubes as of December 23, 1998. As one can see in the figure rather shorter bars indicate that corresponding tubes have been replaced at least once or more. 


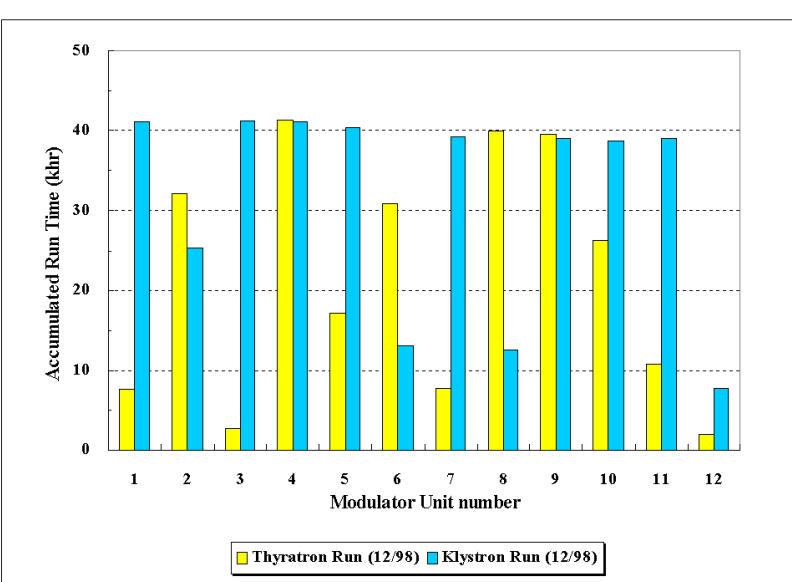

Figure 1: Run time statistics of all klystron and thyratron tubes (as of December 23, 1998). Klystron : M01 : SLAC 5045 tube, M02 : $2^{\text {nd }}$ tube (1995/8/15, magnet coil shorting), M06 : $2^{\text {nd }}$ tube (1997/2/25, gun arcing), M08 : $2^{\text {nd }}$ tube (1997/3/28, heater open), M12 : new module (1997/10/14, system upgrade), Thyratron : ITT F-303 : 8 tube (M01, M04, M07, M08, M09, M10, M11, M12), EEV CX1836A : 2 tube (M03, M05), LITTON L-4888 : 2 tube (M02, M06)

Table 2: K\&M system availability of the PLS linac.

\begin{tabular}{|l|r|r|r|r|r|r|}
\hline $\begin{array}{l}\text { Operation } \\
\text { period }\end{array}$ & 1994 & 1995 & 1996 & 1997 & 1998 & Total \\
\hline $\begin{array}{l}\text { Total no. of } \\
\text { modulators }\end{array}$ & 11 & 11 & 11 & 11 & 12 & 11.2 \\
\hline $\begin{array}{l}\text { Operation } \\
\text { time (hr) }\end{array}$ & 2928 & 7152 & 6432 & 7128 & 6816 & 30456 \\
\hline $\begin{array}{l}\text { Total failure } \\
\text { counts }\end{array}$ & 103 & 175 & 131 & 130 & 289 & 828 \\
\hline $\begin{array}{l}\text { Total down } \\
\text { time (hr) }\end{array}$ & 563 & 1076 & 413 & 529 & 468 & 3049 \\
\hline $\begin{array}{l}\text { Modulator } \\
\text { MTTF (hr) }\end{array}$ & 313 & 450 & 540 & 603 & 283 & 412 \\
\hline $\begin{array}{l}\text { System } \\
\text { MTTF (hr) }\end{array}$ & 28 & 41 & 49 & 55 & 24 & 37 \\
\hline $\begin{array}{l}\text { MTTR } \\
\text { (hr/failure) }\end{array}$ & 5 & 6 & 3 & 4 & 2 & 4 \\
\hline $\begin{array}{l}\text { Availability } \\
\text { (\%) }\end{array}$ & 81 & 85 & 94 & 93 & 93 & 90 \\
\hline
\end{tabular}

In fact we have replaced total 3 klystrons and 15 thyratrons during the total $\sim 430,000-\mathrm{hr}$ of operation time (run time sum of all $12 \mathrm{~K} \& \mathrm{M}$ modules). Machine availability analysis has been performed based on the data using the techniques described in detail in reference [2]. The results are summarized in Table-2.

During the early phase of the operation, from the late 1993 to early 1995 , relatively low machine availability had been obtained. This is due to the maintenance crew training as well as system debugging exercise. Most of time for the repair had been spent for the extensive system diagnostics. The major changes that we implemented at the beginning of 1996 were the computer controlled automatic static fault reset and the modification of the circuit breaker (CB) trip interlock. They greatly contributed to the improved availability reaching over $90 \%$ as shown in the Table-2.

It has been observed that the most frequent system fault is the circuit breaker (CB) trip. This is mainly due to the problems in thyratron recovery characteristics which depend on the elaborate reservoir ranging (hydrogen gas pressure control in the tube). Thyratron tubes require ranging adjustment, and according to our experience they are very sensitive to the effects which may cause internal gas pressure change. Once out of normal operating point, self-fire or miss-fire can occur.

Other occasional troubles were corona discharges that are found to occur when there are bad contacts in high voltage components. It has been found also that even a small corona discharge disturbs the ground potential, which are configured to have a single point ground connection inside the modulator, causing noise interference in digital displays as well as SCR phase controls.

\section{CONSTRUCTION OF THE MK12 MODULE}

The MK12 module of the linac system has been constructed and operated. This contributes to an improvement of the linac energy margin. The installation view of MK12 system in linac tunnel is shown in Fig. 2. The MK12 module consists of two accelerating columns supplied with the rf power by one klystron of $80 \mathrm{MW}$ peak and in-house made modulator of 200 MW peak and one pulse compressor. The auxiliary systems such as vacuum and cooling water were established through extending the existing systems. At commissioning, we obtained the maximum beam energy of about $147 \mathrm{MeV}$.

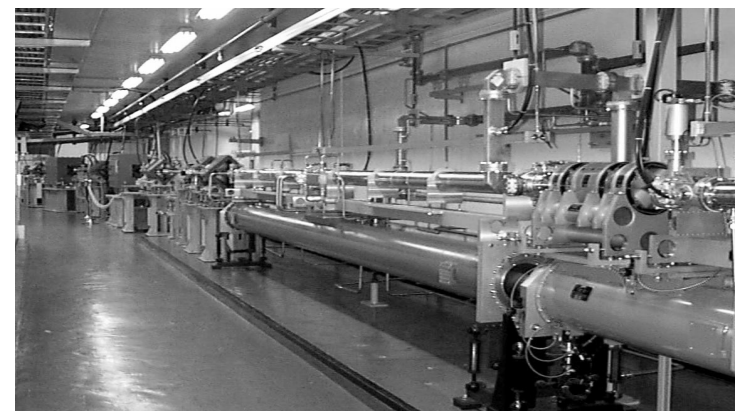

Figure 2: Installed view of the MK12 module in linac tunnel.

\section{ELECTRON BEAM PARAMETER MEASUREMENT}

We are under measurement of electron beam parameters such as the transverse emittance, bunch 
lengths and others. In standard injection mode into SR, electron beam current of $1 \mathrm{~A}$ is transmitted to the end of the linac. The bunch length data are collected by using an optical transition radiation measurement. The bunch lengths as the usual SR injection were measured to be about 12 ps. Fig. 3 shows the streak camera image of the bunch train in one electron beam pulse. Beam parameter measurements at the pre-injector and linac end will be continued. Details of the beam measurement result can be found elsewhere [3].

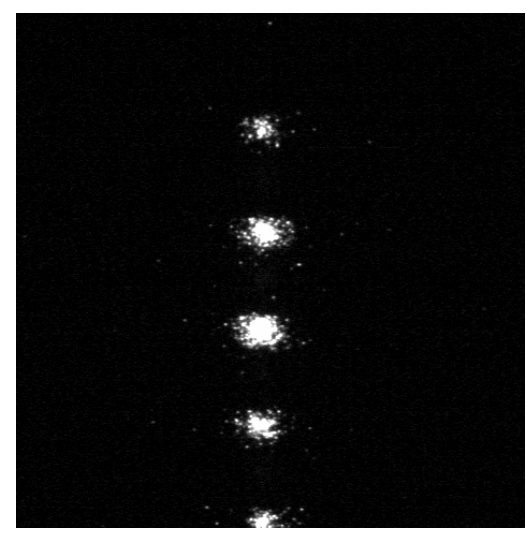

Figure 3: An example of streak camera image of the bunch train in one beam pulse

\section{OPERATIONAL CHARACTERISTICS OF COOLING WATER SYSTEM}

The total operation time of the PLS linac cooling water system has reached about 38,000 since its normal operation from Dec. 1993. At present, the cooling water system shows $99 \%$ availability. The status of system troubles or faults has been daily checked, and maintained during the regular preventive maintenance period. The temperature control within $45 \pm 0.2{ }^{\circ} \mathrm{C}$ for the rf phase stability of accelerating components has been successfully conducted with precision closed-loop cooling water system temperature controllers.
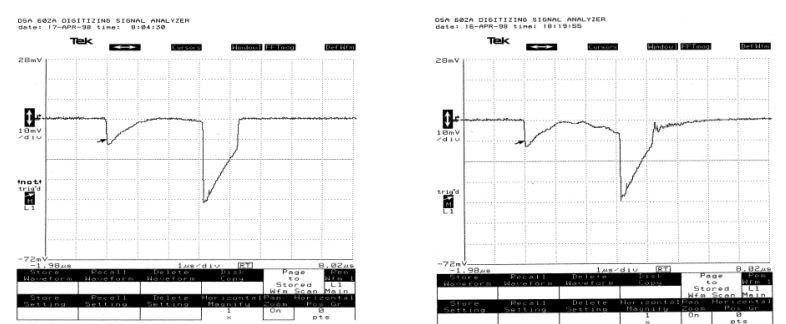

Figure 4: The rf waveform of pulse compressor output power; within temperature control of $45 \pm 0.2{ }^{\circ} \mathrm{C}$ (left) and beyond temperature control of $45 \pm 0.5^{\circ} \mathrm{C}$ (right)
An example of the output power waveform of pulse compressor is shown in Fig. 4. Through the periodic tuning test, the system is optimized so that the rf phase of the linac accelerating components including pulse compressors is sustained very stable by adjusting temperature control variation of the structures.

\section{SUMMARY}

It has been over 5 years since the PLS 2-GeV linac has started its normal operation. We have analyzed the klystron modulator system performance record for the period, which is the major source of the beam injection failure. It is observed that the average lifetime expectancy of the klystron is over 25,000-hr, and it is getting longer. Lifetime of the thyratron tube also appears to be reasonable except the occurrence of the infant failure, however the major improvement is necessary for the reservoir control which is the main source of the system trouble. The machine availability statistics of the K\&M system for the beam operation mode is calculated to be over $90 \%$. It appears that there are still lots of rooms for the improvement of the availability more than $95 \%$ with a smart design of the protection circuits and control schemes. The MK12 module of the linac system was added, and the additional beam energy of about $147 \mathrm{MeV}$ was acquired. The beam bunch length during normal SR injection was measured to be about 12 ps. To research the characteristics of electron beam of linac, beam parameters measurement at the pre-injector and linacend will be continued. The cooling water system has performed with $99 \%$ availability. Through the temperature control within $45 \pm 0.2^{\circ} \mathrm{C}$, the rf phase of pulse compressor output power is maintained very stable.

\section{ACKNOWLEDGEMENTS}

Authors gratefully acknowledge the sincere efforts performed by PAL linac division members to keep the PAL linac system at an excellent condition. This work was supported partly by POSCO and MOST, Korea.

\section{REFERENCES}

[1] W. Namkung et. al, "PLS 2-GeV Linac," Proc. of 17th Int'l Linac Conf., Tsukuba, Japan, Aug. 21-26, pp.14-16 (1994)

[2] A.R. Donaldson and J.R. Ashton, "SLAC Modulator Operation and Reliability in the SLAC Era," IEEE Conf. Proc. 20th Power Modulator Symposium, pp.152-156 (1992)

[3] J.Y. Choi, H.S. Kang, S.H. Nam, S.S. chang, “ Measurement of beam characteristics of PLS linac," in these proceedings 